\title{
ARTICLES
}

\section{PERSPECTIVES ON WILDERNESS: RE-EXAMINING THE VALUE OF EXTENDED WILDERNESS EXPERIENCES}

\author{
JANET FREY TALBOT and STEPHEN KAPLAN \\ Psychological Laboratories, The University of Michigan, Mason Hall, \\ Anin Arbor, Michigan 48109, U.S.A.
}

\begin{abstract}
This paper presents results from the final phase of a ten-year research program dealing with the dynamics and the impacts of wilderness experiences. Although these data are from participants in shorter trips than those reported on previously, questionnaire data indicate that responses to the different trips were similar, and that responses from participants of different ages and sexes were also similar. Theoretical issues which emerged from earlier analyses of participants' journals are also re-examined in light of the current data. These earlier results had suggested that an individual's growing perceptual understanding of the surrounding wilderness environment was connected to a wide range of personal insights as well as other psychological benefits. Results from the current data concur with this finding. Furthermore, contrary to alternative hypotheses, feelings of control over the environment were not evident either in the original data or in the current participants' journals. These data suggest that an alternative stance, described as feeling 'at one with' or 'part of' the environment, is more frequent and is generalized to nonwilderness surroundings. Other categories of individual response which complement this non-dominant environmental orientation are also documented in the current data.
\end{abstract}

\section{Introduction}

Wilderness experiences have long been thought to have special impacts on people. Biblical as well as other literary and historical sources include numerous examples of individuals whose encounters with wilderness environments have left them with enhanced perceptions and strengthened feelings of commitment to various causes (James, 1902; Scott, 1974).

A number of recent psychological surveys have illustrated popular beliefs which roughly correspond with these images. Both wilderness users and non-users have been found to share perceptions that experiences in natural environments can be highly satisfying and can offer valuable psychological benefits not often found elsewhere (for reviews see Heimstra and McFarling, 1974; Iso-Ahola, 1980; Kaplan and Talbot, 1983).

While such evidence may be intriguing, it does not, in itself, constitute convincing proof of the value of wilderness experiences. However, efforts to examine the nature and the impacts of these experiences directly by collecting data from participants in wilderness programs have been fraught with methodological difficulties (for reviews see Turner, 1976; Gibson, 1979; Kahoe, 1979; Kaplan and Talbot, 1983). While the combined weight of several studies suggests that some beneficial responses can result from such experiences, most efforts to clarify the nature of these benefits and to demonstrate the dynamics of their emergence have achieved only limited success. 
The following report describes the results of the last in a sequence of research studies which have been somewhat more successful in quantifying the elements of individual response to wilderness experiences. This research has been conducted over a period of ten years, and encompasses a number of distinct phases in which related issues have been examined independently. Perhaps the most interesting theoretical issues raised by the earlier results of this research concern the direct connections between individuals' perceptions of their physical surroundings and their evolving perceptions of themselves and their own purposes. This network of results had not been anticipated, but emerged repeatedly in content analyses of the participants' journals. This finding of the central role of the natural environment in prompting individual changes was central to theoretical discussions questioning the appropriateness of control orientations in everyday environmental interactions (Kaplan and Talbot, 1983). It also figured in the subsequent development of the concept of compatibility as describing person-environment interactions, in which the individual's capabilities and purposes are well-balanced with the pattern of opportunities and constraints found in the physical environment (Kaplan, 1983).

This report focuses on data from participants during two final years of the wilderness program on which this research has been based. Before examining the more theoretically interesting data from the current participants' journals, questionnaire data comparing the responses of participants in both the longer and shorter trips will be compared and examined for differences in response by age and sex. Then, analyses of the participants' journals will be presented. These both support the earlier finding that environmental perceptions prompted significant psychological changes in individuals, and provide further insights regarding control issues raised by the previous results.

\section{Research methods}

The Outdoor Challenge Program has been conducted for 12 years in an extensive wilderness area in Michigan's Upper Peninsula (Hanson, 1973). Following an initial two years as a survival course for teenage boys, the program incorporated an explicit research agenda in 1972. Besides spending two weeks in a large wilderness setting and acquiring wilderness-survival skills, the 129 participants between 1972 and 1979 wrote daily journals and filled out brief questionnaires both during the trips and afterwards. Participants were recruited without reference to the extent of any prior backpacking experience, and fees were kept low in an effort to include as wide a variety of individuals as possible (further details on this phase of the program are available: Kaplan et al., 1979; Kaplan and Talbot, 1983).*

In its earliest years, the Outdoor Challenge Program was conducted in a manner quite similar to the popular Outward Bound system, emphasizing risks and physical hardships. In response to early research findings, however, a number of adjustments were made in the way the program was being conducted. Some endurance tasks and risk-related exercises were dropped, and participants were given food and shelter materials for use during their solos. Such changes gradually altered the program

\footnotetext{
* The Outdoor Challenge Program as well as the associated research effort has been funded throughout the project by the Forest Service, North Central Experimental Station, USDA. Rachel Kaplan has had a central role in these research efforts, and Robert Hanson has guided the Outdoor Challenge Program since its earliest years. We are grateful for their collaboration throughout this project.
} 
from being a survival-dominant experience into one more centered on the natural environment and more closely similar to a typical backpacking excursion.

The initial research done in conjunction with this program dealt with comparisons between wilderness trips and other activities, using pre- and post-measures collected at roughly 6-month intervals. Initial findings indicated that wilderness program participants experienced a variety of benefits, including the development of greater concerns for others, increased self-sufficiency, and more realistic self-assessments, which were not found within control groups (Kaplan, 1974). A subsequent study showed similar findings, and also illustrated that participants in other outdoor programs reflected positive impacts but also some differences in response (Kaplan, 1977), with greater positive changes in self-perceptions found among the wilderness program participants than among either the controls or the participants in the other outdoor programs studied. During later research the comparison groups were dropped, and data collection and analyses focused on the participants' day-to-day responses in an attempt to explore the dynamics of individual response to wilderness. Analyses of these data illustrated that personal benefits developed only gradually and were very broad in scope, and also clarified the central roles which perceiving and functioning in the natural environment played in the development of the benefits which individuals experienced (Kaplan and Talbot, 1983).

During 1980 and 1981, due to financial constraints and time considerations, the trips were shortened from two weeks to nine days in total length. Backpacking and orienteering remained the primary daily activities, and the latter portion of the trips again included a solo experience lasting approximately 48 hours. As in earlier years, the 49 program participants contributed to the final phase of this research effort by writing journals and filling out questionnaires during their trips.

\section{Responses to Wilderness Experience}

\section{Immediate assessments}

In both the shorter and the longer versions of the program, participants filled out a set of questionnaires immediately before returning home. Four open-ended items were included in these questionnaires, asking participants to describe the best, the worst and the hardest things about their trip, and asking them how they felt they were changed, if at all, by this experience. In order to compare the immediate assessments of this experience, summaries reflecting the answers of all the participants in the shorter trips were compared with summaries from a representative sample of 35 of the 129 participants in the longer trips.

The answers to each of these four questions were summarized according to the six most frequent response categories.* Statistical tests were then conducted for all responses which were mentioned by at least $20 \%$ of the participants. The responses from participants on the shorter and longer trips were compared, as were the responses of adult and younger participants, and males and females.

The answers to these questions, as presented in Table 1, illustrate that these trips have many positive qualities, but that they encompass significant difficulties as well. Among the best elements, participants mentioned the beauty of their surroundings, their experiences during solo, and the lack of time pressures during the trips (ap-

* Two individuals coded these short-answer responses independently. The reliability coefficient for the two codings was 0.99 . 
TABLE 1

Comparisons in last day assessments of wilderness trips ${ }^{a}$

\begin{tabular}{|c|c|c|c|}
\hline \multirow[b]{2}{*}{ Response Categories } & \multicolumn{3}{|c|}{ Statistical comparisons ${ }^{\mathbf{b}}$} \\
\hline & $\begin{array}{c}\text { Shorter/Longer } \\
(47 / 35)\end{array}$ & $\begin{array}{l}\text { Adults/Teens } \\
\qquad(36 / 46)\end{array}$ & $\begin{array}{l}\text { Males/Females } \\
(30 / 52)\end{array}$ \\
\hline \multicolumn{4}{|l|}{ What were the best things? } \\
\hline Coping with things, learning & - & Adults & - \\
\hline Trip activities & - & - & Males \\
\hline The natural surroundings & - & - & - \\
\hline The solo & 一 & - & - \\
\hline The peacefulness, relaxed pace & - & - & - \\
\hline What were the worst things? & - & - & - \\
\hline Trip activities & - & - & - \\
\hline Natural elements (bugs, etc.) & - & - & - \\
\hline The hiking & & & \\
\hline What were the hardest things? & - & - & - \\
\hline The solo & & - & \\
\hline The hiking & Short trips & & Males \\
\hline \multicolumn{4}{|l|}{ Will you be different now? } \\
\hline Try to slow down and simplify & - & - & - \\
\hline Greater nature involvement & Long trips & - & - \\
\hline Be closer to, kinder to others & - & - & - \\
\hline Be more independent and decisive & Short trips & - & - \\
\hline
\end{tabular}

${ }^{a}$ The table includes all responses which were given by at least $20 \%$ of the samples. Significant differences were the results of Student's $t$-tests, with table entries indicating those whose responses were statistically higher.

${ }^{b}$ Cases are indicated at the top of each column. Questionnaire responses were only available for 47 of the 49 participants in the shorter trips. For statistical comparisons, responses were summarized over eight subsamples; $\mathrm{d} f=3,3 ; P<0 \cdot 10$.

preciating 'the peace and calm', and feeling 'no time-consciousness'). A variety of camping activities (setting up camp, eating, telling stories around the fire) were recalled as being the best parts of the trip, and various personally difficult experiences were valued as demonstrating the individual's growing ability to cope with daily challenges.

Not all memories were so positive, however. In mentioning the worst elements, participants frequently noted some of the more mundane camping chores (washing dishes, having to cook) and the more irritating environmental elements such as insects, the swamps ('muddy, wet, smelly and bored') and the rain. Hiking that was too strenuous or too lengthy was mentioned as being both among the worst and among the most difficult or challenging aspects of the trips. And the solo experience, besides being among the best parts of the trip, was also mentioned as among the most difficult for a number of participants.

Finally, when asked if they felt these experiences had changed them, many of the participants reflected a sense that they wanted to live life more simply and slowly in the future because of these experiences (to 'look more closely, take my time', to 'consume less, and simplify'). Many also felt a more compelling interest in the world of nature, and felt they would be more considerate of their family and friends ('just an opener and nicer person'). They also wanted to be careful to make decisions about their lives which reflected their own priorities rather than others' values ('a 
lot of things I thought were important really are not', I'm 'more determined to change what I don't like').

The results of statistical comparisons between the shorter and longer trips and between participants of different ages and different sexes are also shown in Table 1. These reveal both a large number of similarities and a few differences in response to these experiences. Responses concerning the best and worst elements of the shorter and longer trips were quite similar: both the type of answer given and the frequencies of each different response were equivalent for participants on all the trips. However, there were a few differences in response to the two remaining questions. Participants in the shorter trips identified hiking as one of the hardest aspects of the program significantly more often than did the participants in the longer trips. And in evaluating the difference they felt the program would make in their lives, participants in the shorter trips mentioned more often than the others an increased desire to choose and to control their own activities. In contrast, participants in the longer trips more frequently mentioned perceiving a larger and more valued involvement with nature as resulting from their trip experiences.

Comparisons of the responses of adults and teenagers resulted in only one finding of a significant difference in response. Adults were more likely than the younger participants to say that coping with daily problems was among the best elements of the trip for them. All other evaluations of these experiences and their impacts were equivalent for the older and younger participants.

Statistical comparisons between males and females also reflected a largely similar pattern of response to these experiences. Males made more concrete assessments of their experiences in two instances, being more likely to say that specific trip-related activities were among the best things in the trip, and that hiking was among the most challenging elements for them. In other categories of response, no significant differences were found between male and female participants.

Taken together, the answers to these questions illustrate the many ways in which wilderness experiences are valued. Such trips take place in fascinating physical surroundings, and involve enjoyable activities. But enjoyment is not the only value which is perceived in these experiences. They also offer opportunities to learn, to cope with difficulties, and to reflect on one's character and future plans. These data suggest that wilderness experiences can prompt some change in the participants' overall perspectives on life and their own priorities, as well as their preferred involvements. The results of statistical comparisons suggest that the impacts of these experiences are largely similar for different individuals, and for participants in somewhat different programs as well.

Data collected from additional questionnaires completed by the participants in the current trips (R. Kaplan, 1984) give further evidence of individuals' positive responses. These data illustrate high levels of appreciation for the solo and other aspects of the trip, as well as the development of increased sensitivity to nature, and positive changes from the trip's beginning to its end in individual ratings of self-confidence, psychological energy and general well-being.

The development of individual response to wilderness

The kinds of individual response to wilderness experiences which are discussed above seem to approximate those so eloquently spoken of in literary and historical accounts. These trips offer enjoyable and compelling learning experiences which have 
implications for individuals' views of themselves and the world. Beyond re-examining the effects of these experiences, a further examination of the development of individual response over the course of the trips was also undertaken, in order to validate and to expand on the earlier results.

For these examinations, a content analysis of the journals written during the shorter trips was conducted, using methods similar to those used in analysing journals from participants during one year (1976) of the longer trips. For the earlier analysis, categories representing comments which appeared in at least one-third of the journals had been defined. Coded summaries of the journals were then prepared, indicating the frequency with which each topic was mentioned. Clusters of topics were subsequently identified, using the criterion that the correlations between each pair of topics within the cluster was at least 0.50. Alpha values (Cronbach, 1951), representing the internal consistency or coherence of a cluster of items, were computed for these dimensions of individual response.

For the current analysis, the previous list of topics was repeated, and the list was expanded to express a number of more abstract issues raised by the previous analysis. By repeating the previous topics, the elements of individual response which were related to the emergence of psychological benefits could be revalidated. In addition, by examining new concepts defined as the result of the previous analysis, the network of theoretically related concepts might be enriched. Even though these other responses might not be found as frequently as those studied initially, documenting their presence and studying the relationships among them might offer new theoretical insights, and might augment the understanding of the dimensions of response identified initially.

Of particular interest in this expanded inquiry was the possibility of exploring individual feelings of control over the environment. This response was not investigated earlier, both because it was outside the scope of the initial investigation and because it was not found to be a frequent response among the program participants. However, others conducting research on the impacts of wilderness programs have claimed that the individual's increased ability to control the environment is a critical outcome upon' which the benefits of such experiences depend (Newman, 1980). Further evidence on the participants' feelings about control might be helpful in responding to these claims.

Additional topics which were investigated in the current participants' journals described an alternative to the control position, described as feeling a part of or 'at one with' the environment. This category of response was found in some of the journals originally, and seemed more likely to emerge from the wilderness experience than feelings of control over the environment. While this non-dominant environmental orientation and its hypothesized correlates were not among the most frequent topics in the earlier journals, the journal analysis had suggested they might be conceptually related to some of the more common categories of individual response.

\section{Enhanced perceptions of the environment and the individual}

The previous journal analysis had suggested that a wide range of individual benefits emerged directly from the development of enhanced environmental perceptions in the wilderness. Despite many early feelings of apprehension, the participants were fascinated by an environment which was radically different from their everyday surroundings, and upon which they had to depend for their comfort and safety. They began to notice more of the physical details of their environment, and developed an 
TABLE 2

Comparisons in perceptual response to wilderness

\begin{tabular}{|c|c|c|c|c|}
\hline \multirow[b]{3}{*}{$\begin{array}{l}\text { Categories in dimension } \\
\text { (with examples from journals) }\end{array}$} & \multicolumn{4}{|c|}{ Journal entries } \\
\hline & \multicolumn{2}{|c|}{$\begin{array}{c}\text { Shorter Trips } \\
(\text { Alpha }=0.70)\end{array}$} & \multicolumn{2}{|c|}{$\begin{array}{c}\text { Longer Trips } \\
(\text { Alpha }=0.86)\end{array}$} \\
\hline & $\begin{array}{l}\% \text { of } \\
\text { sample }\end{array}$ & $\begin{array}{c}\text { Mean/ } \\
\text { journal }\end{array}$ & $\begin{array}{c}\% \text { of } \\
\text { sample }\end{array}$ & $\begin{array}{l}\text { Mean/ } \\
\text { journal }\end{array}$ \\
\hline $\begin{array}{l}\text { Notice nature details } \\
\text { (I could begin to see, noticing } \\
\text { how trees creak, ripples in the } \\
\text { water, the sun's progression) }\end{array}$ & 86 & $2 \cdot 2$ & 69 & $3 \cdot 2$ \\
\hline $\begin{array}{l}\text { Comfortable in the woods } \\
\text { (feel really at home, could stay } \\
\text { here forever, this is real) }\end{array}$ & 55 & $1 \cdot 2$ & 45 & $2 \cdot 2$ \\
\hline $\begin{array}{l}\text { Awe and wonder about nature } \\
\text { (a special thrill, so hard to } \\
\text { believe, the bear was incredible) }\end{array}$ & 62 & $2 \cdot 1$ & 42 & $2 \cdot 2$ \\
\hline $\begin{array}{l}\text { Self-insights } \\
\text { (really feel like yourself here, } \\
\text { learning about me, I really grew, } \\
\text { surprised at my feelings) }\end{array}$ & 84 & $3 \cdot 7$ & 42 & $2 \cdot 7$ \\
\hline
\end{tabular}

enhanced appreciation for their surroundings. In time, daily functioning in these surroundings came to be accompanied by a strong sense of comfort-described not as physical ease but rather as an appreciation for the ease of fitting in with the wilderness environment. The participants' growing environmental awareness was often accompanied by similar increases in perceived levels of self-knowledge, and by sensations of awe in relation to the natural environment and the events observed there.

From a theoretical perspective, these responses themselves are not as interesting as are the interrelationships which were discovered among them. The correlational structure found within the earlier journal data suggested that neither the specific enjoyments of the trips nor the difficulties which the trips encompassed were connected to the more internalized levels of response. While both enjoyments and stresses were present, as the questionnaire data discussed above indicate, the structure of the journal data indicated that it was the individual's developing perceptions which were directly related to each other, that the ways of perceiving which were acquired through experiences in wilderness surroundings had direct consequences for individuals' views of their own abilities and interests and for their views of the larger world as well.

Table 2 presents the Alpha coefficient of the 'Perceptual Change' cluster of response, both as reflected in the current journals and as originally found in journals kept by the participants in the longer trips, along with a description of the contents of this dimension.* This dimension of response clearly expresses the connection

* Two individuals coded the current journals independently. The reliability coefficient for the two codings was 0.69 . The frequencies used in constructing Table 2 were obtained by taking the average of the two independent coding sets. 
between the participants' interactions with their surroundings during the wilderness experience, and their feelings about themselves. As individuals began to notice new and sometimes subtle details in their surroundings, their feelings of personal comfort increased. This often occurred despite individuals' expectations that their time in the woods would be an anxious and disturbing one, and to some this new sense of comfort was an 'amazing' development. The participants' emotional response to the natural environment-both these feelings of comfort and the emerging feelings of awe and wonder-gradually generalized to include their feelings about themselves as well. As one participant expressed it, 'those feelings and rhythms transfer themselves to us without our ever being aware of the process'. The participants felt more selfaware, sometimes expressed simply as feeling 'more like myself' but at other times expressed more fully (e.g. 'maybe this is the secret, what is most dramatic is quiet and it escapes us because we expect great and preponderous things. I think the real giving is quiet and the real sharing is quiet').

Table 2 also presents information on the percentage of participants mentioning each of the categories in the 'Perceptual Change' cluster, along with the frequencies with which each of the topics was mentioned. The relatively stable findings in reference to this dimension, which connects individuals' environmental- and selfperceptions, lend additional empirical support to the analytic framework developed earlier. There seem to be certain patterns of psychological response, involving the development of environmental sensitivity and the implications of this learning for one's self perceptions, that are basic to extended encounters with wilderness surroundings.

Control orientations, and some alternatives

Evidence regarding the participants' control feelings, although not found often enough in the earlier journals to permit systematic analysis, was investigated in the journals kept by the current wilderness program participants. However, comments reflecting feelings of control over one's surroundings were again found only infrequently, being present in only 7\% of the current participants' journals.* Again, this was not considered to be sufficient to justify further analysis. The implication of this result, as suggested also by the results of earlier phases of this research effort, is that feelings of control are not common elements of individuals' response to wilderness experiences, and are not central to the emergence of psychological benefits.

However, as mentioned above, the earlier analysis had suggested that an alternative response, described as feeling 'at one with' or 'part of' one's surroundings, might be found with some frequency among the participants. This non-control orientation towards the environment might also be related to other potential responses which had been identified as the result of the theoretical analysis of the earlier journals' structure.

Table 3 presents the Alpha coefficient and describes the contents of a cluster of items which were found in the current journals and which were related to this feeling of oneness with the environment. $\dagger$ As the contents of this table

\footnotetext{
* Regarding the occurrence of control-related sentiments, there was agreement between the two coders on $95 \%$ of the current participants' journals.

† The reliability coefficient between the two coders for the categories included in this cluster was 0.68. Frequencies given reflect the average of the two coding sets. This cluster of response was identified through the combined use of the SSA-3 Nonmetric Factor Analysis Program (Lingoes, 1972) and the ICLUST Clustering Algorithm (Kulik et al., 1970).
} 
TABLE 3

Perceptions of oneness with the environment

\begin{tabular}{|c|c|c|}
\hline \multirow[b]{2}{*}{$\begin{array}{l}\text { Categories in dimension } \\
\text { (with examples from journals) }\end{array}$} & \multicolumn{2}{|c|}{$\begin{array}{c}\text { Journal entries for } \\
\text { shorter trips } \\
(\text { Alpha }=0 \cdot 88)\end{array}$} \\
\hline & $\begin{array}{l}\% \text { of } \\
\text { sample }\end{array}$ & $\begin{array}{l}\text { Mean/ } \\
\text { journal }\end{array}$ \\
\hline $\begin{array}{l}\text { Oneness with environment } \\
\text { (feel close to the earth, } \\
\text { not an intruder, related to } \\
\text { the earth and the animals) }\end{array}$ & 26 & $1 \cdot 6$ \\
\hline $\begin{array}{l}\text { Feelings of awe and wonder } \\
\text { (so sacred and mysterious, } \\
\text { spiritual, a sanctuary) }\end{array}$ & 57 & 1.4 \\
\hline $\begin{array}{l}\text { Environmental coherence } \\
\text { (everything in harmony, simple } \\
\text { yet complex, nothing's either good } \\
\text { or bad, it's all part of a system) }\end{array}$ & 17 & 1.6 \\
\hline $\begin{array}{l}\text { Simplicity of woods living } \\
\text { (things get basic, days reduced } \\
\text { to a few simple tasks, no frills, } \\
\text { just living and enjoying the world) }\end{array}$ & 24 & $1 \cdot 1$ \\
\hline $\begin{array}{l}\text { Feel refreshed, restored } \\
\text { (feel better than I have in years, } \\
\text { mentally and physically renewed, } \\
\text { very relaxed and alive) }\end{array}$ & 24 & $1 \cdot 2$ \\
\hline $\begin{array}{l}\text { Nature/city comparisons } \\
\text { (quickly adapt to not having } \\
\text { phones \& cars, the commotion } \\
\text { of society, the frustrations) }\end{array}$ & 67 & $1 \cdot 4$ \\
\hline
\end{tabular}

a This category represents a slightly narrower coding of the 'Awe and wonder about nature' category as shown in Table 2, including only specific references to a somewhat spiritual quality in the surroundings.

indicate, the participants' feelings of awe and wonder and their sensitivity to the spiritual elements of the environment were related to this 'oneness' response. Their awareness of environmental coherence, of the increasingly apparent harmony within the environment ('things are not as haphazard as they appeared to me originally'), is also related to this feeling, as are an appreciation of the simplicity of living in the woods; strong sensations of physical and mental renewal; and specific comparisons between one's experience in the woods and the irritations of daily life (activities here are 'very strenuous yet less frustrating; at home, there are few physically strenuous activities but many mentally strenuous ones').

\section{Conclusions and Implications}

These findings are largely in agreement with results from earlier phases of this research program. Participants with varied backgrounds have found their experiences in this wilderness hiking program to be enjoyable and compelling. They also indicate that 
their orientations to life have been affected by these experiences. They see their lives afterwards as being different from before-less cluttered, more mindful of those to whom they are close, and more focused on what they personally consider valuable.

The findings based on journals kept by participants in the current trips are also in agreement with earlier results. A crucial outcome of these wilderness trips appears to be the emergence of a shift in perceptual awareness which encompasses more than the acquisition of knowledge about a specific type of physical environment. Again, the evidence suggests that the processing of environmental perceptions has generalized to include individuals' feelings about themselves.

Accompanying this response, the data from the current participants' journals also suggest that a non-control-oriented approach to life and to one's surroundings has developed through the course of this experience. This orientation is perceived both as being quite comfortable and as being harmonious with what has come to be understood as an awesome physical reality.

In analysing the meaning and functions of cultures, Kluckhohn (1953) proposed that gaining an understanding of the proper relationship between man and nature is one of five inevitable questions to which cultures must provide answers. The answers to this question are varied: humans can be perceived as subjugated to nature, as being in harmony with natural forces, or as dominating nature. The data presented here suggest that wilderness hiking experiences can deeply affect individuals and their understanding of this critical issue. For these individuals the answer to this question is often clear and compelling. Far from concluding that humans should dominate or 'control' natural forces, as others have suggested, they become convinced that living with nature is both more appropriate and more satisfying.

The data presented here give ample evidence that a compelling set of psychological responses to wilderness occur; they do not, however, address whether similar benefits might be experienced in other environments. Czikszentmihalyi (1975) has analysed certain experiences which share many properties with the psychological events which have been described here. He has used the terms 'autotelic' and 'flow' to describe experiences which are pursued for their own intrinsic rewards rather than for any resultant outcomes. These are activities in which one loses track of time; feels a loss of self and a sense of oneness; and senses a coherence or a lack of contradictions in the type of actions required. Czikszentmihalyi's analysis focuses on the pursuits of highly skilled individuals, such as surgeons, chess experts and gifted athletes. His description of autotelic activities is similarly limited, concentrating on certain pursuits which have explicit rule systems and in which the perceptual field is limited to a narrow range, such as a gameboard or an artist's canvas. The analysis of wilderness experiences which has been presented here, in contrast, deals with ordinary individuals pursuing commonplace activities within a particular kind of environment. Rather than being a response to a constrained or limited sensory field, in this situation the psychological effect appears to be dependent upon the unlimited scope of the environment itself.

The evidence presented here suggests that the wilderness environment is one where the experience of compatibility, the harmonizing of one's own capabilities and inclinations with the opportunities and limitations present in the physical surroundings, is particularly likely (Kaplan, 1983). To a large degree, this is the result of qualities which are inherent both in the individual and in this particular type of environment. The wilderness is composed of fascinating content, and it presents a coherent world 
of considerable scope, one that readily captures one's full attention. The individual is inclined to take an active part in the functioning of this environment, and to become immersed in observing its physical details. The richness of this experience, the satisfying quality of functioning within a supportive physical setting, often leads individuals to deeper levels of personal understanding, and to convictions that the ways in which they conduct their lives in their ordinary surroundings should also be different.

The data reviewed in this report echo the descriptions of others who have spoken perhaps more eloquently from personal experience. A trip to the woods has the potential to be more than an enjoyable vacation or, as non enthusiasts would view it, a grueling physical endurance test. The commonplace experiences of ordinary individuals in these surroundings seem to lead to psychological effects which the participants themselves may not have anticipated. Individuals with unusual talents or unusual training apparently are able to control events within a limited stimulus field and to achieve a heightened and beneficial psychological state, characterized by strong feelings of coherence and compatibility. Wilderness seems to offer the same or similar benefits to individuals ranging considerably more widely in ability and background.

\section{References}

Cronbach, L. J. (1951). Coefficient alpha and the internal structure of tests. Psychometrika, 16, 297-335.

Czikszentmihalyi, M. (1975). Beyond Boredom and Anxiety. Washington, D.C.: Jossey-Bass.

Gibson, P. M. (1979). Therapeutic aspects of wilderness programs: a comprehensive literature review. Therapeutic Recreation Journal, 13, 21-33.

Hanson, R. (1973). Outdoor Challenge and mental health. Naturalist, 24, 26-30.

Heimstra, N. W. and McFarling, L. H. (1974). Environmental Psychology. Monterey, CA: Brooks/Cole.

Iso-Ahola, S. E. (1980), The Social Psychology of Leisure and Recreation. Dubuque: William C. Brown.

James, W. (1902). The Varieties of Religious Experience. New York: Holt.

Kahoe, R. D. (ed.) (1979). Wilderness therapy. Wilderness Psychology Newsletter, 2.

Kaplan, R. (1974). Some psychological benefits of an Outdoor Challenge Program. Environment and Behavior, 6, 101-116.

Kaplan, R. (1977). Summer outdoor programs: their participants and their effects. In Children, Nature and the Urban Environment: Proceedings of a Symposium-Fair (USDA Forest Service General Technical Report NE-30). Upper Darby, PA: USDA Forest Service Northeastern Experimental Station, pp: 175-179.

Kaplan, R. (1984). Wilderness perception and psychological benefits: an analysis of a continuing program. Leisure Sciences, 6, 271-289.

Kaplan, R., Kaplan, S. and Frey, J. (1979). Final report: assessing the benefits of a natural area experience, and orientation to a wilderness area experience. Cooperative agreements 13-451 and 13-452, North Central Forest Experimental Station, Forest Service, USDA.

Kaplan, S. (1983). A model of person-environment compatibility. Environment and Behavior, $15,311-332$.

Kaplan, S. and Talbot, J. F. (1983). Psychological benefits of a wilderness experience. In I. Altman and J. F. Wohlwill (eds), Behavior and the Natural Environment, Vol VI of Human Behavior and Environment. New York: Plenum.

Kluckhohn, F. R. (1953). Dominant and variant value orientations. In C. Kluckhohn, H. A. Murray and D. M. Schneider (eds), Personality in Nature, Society and Culture. New York: Knopf. 
Kulik, J. A., Revelle, W. R. and Kulik, C-L. (1970). Scale construction by hierarchical cluster analysis. Unpublished, University of Michigan.

Lingoes, J. C. (1972). A general survey of the Guttman-Lingoes nonmetric program series. In R. N. Shepard, A. K. Romney and S. B. Nerlove (eds), Multidimensional Scaling Volume I. New York: Seminar.

Newman, R. S. (1980). Alleviating learned helplessness in a wilderness setting: an application of attribution theory to Outward Bound. In L. J. Fyans, Jr. (ed.) Achievement Motivation: Recent Trends in Theory and Research. New York: Plenum.

Scott, N. R. (1974). Toward a psychology of wilderness experience. Natural Resources Journal, 14, 231-237.

Turner, A. L. (1972). The influence of Outward Bound School experience on the self-concept of adolescent boys. Ph.D. Dissertation, Boston University. Ann Arbor: University Microfilms International.

Manuscript received: 17 October 1984 Revised manuscript received: 29 October 1985 